\title{
Por uma Biagraphia: notas sobre o registro da violência
}

Enrique V. Nuesch ${ }^{1}$

RESUMO: Este ensaio trata de levantar questões teóricas acerca da possibilidade de se registrar discursivamente a experiência da violência no campo das ciências humanas. Para isso, analisaremos certas posições de Bourdieu sobre a relação entre a experiência e a linguagem e as confrontaremos com alguns pontos de vista de Jacques Derrida no que se refere à sua leitura da linguística de Saussure. Proporemos, assim, que esse registro discursivo da violência dever-se-ia pôr sob a rubrica de uma bia-graphia ("escrita da violência”), que se inscreve, ainda que de forma elusiva, em toda e qualquer biografia ("escrita da vida").

PALAVRAS-CHAVE: Bourdieu, Derrida, violência, linguagem.

ABSTRACT: This paper aims at discussing, from a theoretical perspective, the possibility of registering, in the discourse of the Humanities, the experience of violence. To do so, I analyze the relationship between experience and language as defined by Bourdieu and confront it with some of Derrida's ideas in relation to Saussure's linguistics. I will argue that the discursive register of violence should be done as a bia-graphy ("writing of violence") which is inscribed - though in an elusive form - in each and every biography ("writing of life").

KEYWORDS: Bourdieu, Derrida, violence, language

Biagraphía: do grego Bía (violência) + graphé (escrita). A Biagraphía será o campo das ciências humanas que estudará e determinará os métodos e modos de notação da violência na análise do discurso. Ela adquire o seu direito de existência na medida em que se ergue a partir do encontro, digamos, violento, entre o discurso científico e o seu limite, ou, melhor, a sua fronteira - num sentido ainda por determinar que, veremos, não diz respeito apenas às ciências humanas. Mas, justamente por isso, por surgir do encontro com um limite, exige, antes de tudo, antes de exercer o direito de fazer prescrições de ordem prática à pesquisa, uma reflexão filosófica, que nos faça compreender o sentido desse limite, dessa fronteira.

Bía: um fato marginal, de ordem fonética e fonológica, tem o poder de nos levar ao centro da reflexão: a violência que estudamos ao analisar discursos sobre a violência é a experiência da violência em sociedades ou indivíduos concretos, é aquela que se exerce ou é sofrida por mulheres e homens, que faz parte ou se inscreve na vida, na Bíos. A Bía se inscreve na Bíos. Uma Biographia não pode estar completa sem ter a sua parte biagraphica, na medida em que não há ser humano que jamais tenha experimentado a violência, pelo fato de ela se estender desde a agressão física ou verbal explícitas até as diversas dimensões do plano simbólico. Repetimos: a Bía se inscreve na Bíos, e a violência com a qual o analista se depara em sua pesquisa é aquela experimentada por pessoas concretas em suas vidas.

${ }^{1}$ Doutorando em Estudos Literários pela Universidade Estadual de Londrina - Londrina. Mestre em Literatura pela Universidade Federal de Santa Catarina. Contato: enrique_nuesch@yahoo.com.br. 
Se definir exaustivamente o que é a violência pode não ser exequível aqui; podemos, ao menos, assinalar uma ideia que, cremos, se mantém constante em todos os tipos de violência que se possam situar dentro desse espectro que vai do físico ao simbólico: na acepção em que Aristóteles emprega Bía na Física, quando diz ao longo desse tratado que os corpos têm movimentos "naturais" e "por violência" (bîai), que são "contra a sua natureza" (parâ phýsin). Nessa distinção entre movimentos, a tradução de physis por "natureza" evidentemente nos recoloca um problema que talvez pudéssemos considerar "resolvido": o que é que entendemos por natureza nas ciências humanas.

Lembraríamos que, desde Lévi-Strauss, a sua utilização não se referia mais a uma determinação ontológica do real e sim a um instrumento do método. "O homem em estado natural" e o "homem em estado de cultura (ou de sociedade)", essa distinção apenas metodológica e o gesto de Lévi-Strauss de admiti-la enquanto "apenas" metodológica nos relembra que, tanto quanto para a distinção de um estado de natureza do homem, quanto para a determinação da "natureza do homem" ("homem" sempre entendido como anthropos), o significado de natureza estará sempre suspenso.

Suspenso em seu uso para referir-se a qualquer determinação do homem: um dos esforços mais nobres das ciências humanas é o de lutar contra a "naturalização" do homem, desde os esforços do Fray Bartolomé de las Casas, no séc. XVI, para convencer a coroa espanhola de que os nativos americanos não são um recurso natural, até os dias de hoje, enquanto ainda tem como tarefa desnaturalizar, numa luta que transcende o âmbito acadêmico e alcança o âmbito político, as desigualdades sob as quais vivem tantos grupos humanos (mulher/homem; homossexual/heterossexual...). E, entretanto, podemos ver que a natureza e um estado natural ainda pairam sobre a nossa conceitualidade, em continuidade com Aristóteles: a violência ainda retém em seu conceito a ideia de que algo se passa com um sujeito ou com uma subjetividade (que pode ser coletiva), marcando numa parte da existência um evento que não se identifica com o andar "cotidiano", "rotineiro" (e tantos outros termos utilizados como substitutivos para "normal" e "natural") da sua vida: Bía.

As precauções do método: linguística "insuficiente”, emergência do discurso

Quando se trata, dentre os objetivos de uma entrevista, de uma pesquisa sobre a violência, alguma forma de destaque ou marca distintiva sobre o fluxo de discurso do entrevistado irá se fazer, circunscrevendo dentre as experiências apresentadas a experiência da violência. Quer queiramos ou não, o "contra a natureza" - parâ phýsin - está presente no nosso conceito de violência; seja como for que marquemos ou escrevamos a violência no discurso científico, estamos antes de tudo lendo a violência inscrita sobre-entre-sob o discurso que apresenta uma experiência vivida, lendo a inscrição da Bía, do movimento contra a natureza que altera a natureza da Bíos. Ao delimitarmos a violência na vida, dizemos algo sobre a natureza da vida.

Uma vez que apontamos esta cumplicidade com a ideia de uma natureza que é contrariada pela violência, poderíamos dizer que a Biagraphía iria engajar-se no trabalho de desconstrução das categorias analíticas herdadas da tradição ocidental, mostrando os limites das mesmas. O que esboçamos aqui rapidamente, apontando a dependência do conceito de violência em relação a uma certa ideia de natureza, seria completado pelo
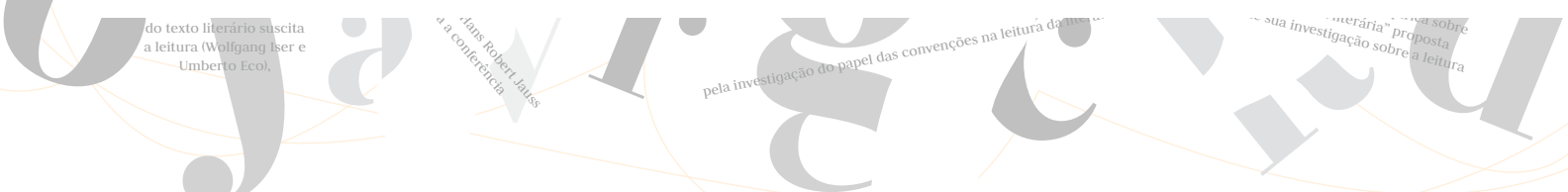
que Clastres fez na sua "Arqueologia da violência", mostrando, entre outras coisas, que a violência pode não ser uma experiência contra a natureza, uma vez que pode se inscrever enquanto etapa cronológica da vida dos sujeitos em grupos humanos que a incorporam enquanto rito de passagem. Nestes casos, contra a natureza seria o fato de um sujeito não ser submetido à violência. Ou então, estes casos simplesmente não são casos de violência e, justamente, são notados ou anotados enquanto violência na perspectiva de um observador que nutre o seu discurso com as categorias da tradição ocidental.

E isto nos leva ao ponto central da reflexão prévia requisitada pela Biagraphía. Ainda que coloquemos sob suspeita o conceito de violência enquanto movimento contra a natureza, operacionalmente continuamos a marcar a violência enquanto experiência singular dentro do discurso de uma experiência vivida. Por isso, antes mesmo de perguntarmo-nos pelo código a ser utilizado no discurso científico, devemos nos perguntar se os códigos de que dispõe o depositário da experiência são capazes de demarcar a experiência da violência em seu discurso. A relação entre experiência e linguagem é a questão. Questão filosófica clássica, de mais de dois mil anos, cujo modo de abordagem aqui, neste esboço da Biagraphía, apenas sugeriremos.

É uma relação entre dois termos. Mas uma relação de co-implicação de modo que a sua abordagem parece exigir que o curso do raciocínio apresente um movimento de passagem entre um termo e outro, chegando ao ponto em que, referindo-se a um, estar-se-á, inevitavelmente, referindo-se ao outro.

Tentemos. O que é experiência de acordo com o discurso das ciências humanas? $\mathrm{O}$ que é experiência em geral? Não encontramos uma formulação que coloque uma definição positiva e unívoca. Podemos, no entanto, supô-la a partir de algumas palavras de Pierre Bourdieu. Não temos uma justificativa para essa escolha, a não ser que se aceite como uma a declaração de uma mera preferência: Bourdieu, porque ele apresenta nos seus escritos certas reflexões críticas acerca da relação que temos em pauta, e no, curso delas, sugere os mesmos limites da experiência e da linguagem; sugere, na medida em que não o faz explicitamente, mas, por virtude da prática de um certo filologismo que o autor denuncia algures enquanto uma mazela da concepção da linguagem mantida por uma certa linguística, pode-se vislumbrar o desponte desses limites.

Vamos às palavras (e a palavra será um dos conceitos, talvez, centrais da sua reflexão) de Bourdieu. Nada melhor que recorrer a um texto de título sugestivo, "Compreender". Neste, o autor fala de uma "escuta ativa e metódica" a ser adotada pelo pesquisador em relação ao seu entrevistado, visando a "reduzir a violência simbólica" que no mais das vezes se instaura na relação pesquisador-entrevistado:

ela [a escuta metódica] associa a disponibilidade total em relação à pessoa interrogada, a submissão à singularidade da sua história particular, que pode conduzir, por uma espécie de um mimetismo mais ou menos controlado, a adotar a sua linguagem e a entrar em seus pontos de vista, em seus sentimentos, em seus pensamentos, com a construção metódica, forte, do conhecimento das condições objetivas, comuns a toda uma categoria. (BOURDIEU, 1997, p. 695) 
"Pontos de vista", "sentimentos", "pensamentos", aos quais se chega pela adoção de uma certa linguagem, através de um mimetismo. Podemos considerar a experiência como a soma ou a resultante dessas três palavras que colocamos entre aspas? Acreditamos que sim, pois mais adiante temos a denominação da "escuta metódica" feita em outros termos, bastante esclarecedores:

Pode-se sem dúvida falar de uma auto-análise provocada e acompanhada: em mais de um caso nós sentimos que a pessoa interrogada aproveitava a ocasião que the tinha sido dada de ser interrogada [...] para realizar um trabalho de explicitação, gratificante e doloroso ao mesmo tempo, e para enunciar, às vezes com uma extraordinária intensidade expressiva, experiências e reflexões há muito reservadas ou reprimidas. (BOURDIEU, 1997, p. 704-5)

A "escuta metódica" pela "adoção" da linguagem do entrevistado permite, assim, encontrar (e fazer com que o entrevistado as reencontre) as suas experiências e reflexões: seus "pontos de vista", "sentimentos" e "pensamentos" são expressos (por vezes com intensidade) ao longo dessa autoanálise que a entrevista bem conduzida é capaz de provocar. E, nota bene, tal expressão se faz por meio da enunciação.

Deixemos assente, pois, que se espera ser a experiência do entrevistado passível de compreensão através das suas palavras. Podemos disso depreender que a linguagem e a experiência andam, para Bourdieu, juntas? Juntas ao ponto de que sem linguagem não haveria experiência? Isso seria abusivo. Bourdieu não parece ser adepto da posição segundo a qual o limite do mundo é o limite da minha linguagem. Pelo menos se linguagem estiver se referindo à língua, ou seja, um dos "sistemas simbólicos" que são “instrumento de conhecimento e de comunicação" (BOURDIEU, 2003, p. 9). Com efeito, parece ser possível entender que o emprego de linguagem por Bourdieu se refere mais especificamente às idiossincrasias que os usos desse sistema simbólico (a língua) apresentam de acordo com o habitus dos agentes em um determinado campo: assim, ele pode se referir à "linguagem filosófica heideggeriana" (BOURDIEU, 1983, p. 183). Este entendimento é ainda encorajado algumas linhas antes: "Daí resulta que a língua varia segundo o locutor e segundo a relação de produção lingüística, isto é, segundo a estrutura da interação lingüística (no campo de um diálogo, por exemplo) ou segundo a posição do produtor no campo considerado" (BOURDIEU, 1983, p. 182).

A língua é, pois, retomemos, um dos "sistemas simbólicos", "instrumento de conhecimento e de comunicação"; ela não é, pois, condição primeira da experiência, mas é um dos sistemas simbólicos pelos quais se constrói o mundo objetivo. Quem o constrói? Os sujeitos, num consensus. Porém, numa configuração que poderíamos denominar como um circuito: os sistemas simbólicos são estruturas estruturantes, na medida em que estruturam a realidade, mas são estruturas estruturadas, na medida em que nelas os sujeitos encontram as possibilidades de dar sentido ao mundo, ou seja, de estruturar a realidade (BOURDIEU, 2003, p. 8-9).

A questão da gênese histórica dos sistemas simbólicos está fora do escopo da pesquisa social: saber como, na história natural da humanidade, surgiram os sistemas simbólicos é algo que está vedado à pesquisa sociológica, uma vez que o socius (seu ob-
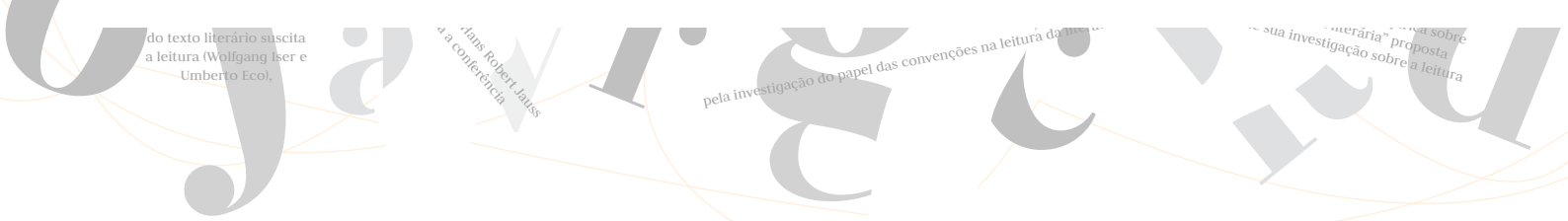
jeto) pressupõe a existência dos sistemas simbólicos, e a arqueologia não o para de confirmar, porquanto todo vestígio de humanidade - sejam inscrições rupestres, sejam utensílios - já demarcam uma divisão do trabalho e, assim, a existência dos sistemas simbólicos em que tal divisão se fundamenta. O estudo de qualquer sociedade - seja ela "primitiva", moderna ou contemporânea - se dá com o dito circuito desde já instaurado, pois, por definição, uma sociedade implica uma divisão social. Veja-se, por exemplo, o estudo de Bourdieu, "Gênese e estrutura do campo religioso": sabemos que língua, religião, arte "etc" (entre aspas, pois não sabemos qual é a abrangência deste cetera) são sistemas simbólicos, e o estudo da gênese do campo religioso pressupõe, de saída, a existência do sistema simbólico denominado religião:

a religião contribui para a imposição (dissimulada) dos princípios de estruturação da percepção e do pensamento do mundo e, em particular, do mundo social, na medida em que impõe um sistema de práticas e representações cuja estrutura objetivamente fundada em um princípio de divisão política apresenta-se como a estrutura natural-sobrenatural do cosmos. (BOURDIEU, 1992, p. 33-4)

Tendo, pois, o campo religioso a sua possibilidade genética no sistema simbólico, este último é o termo de explicação onde se vai procurar a gênese do campo. Não se sai, pois, do circuito mencionado: "existe uma correspondência entre as estruturas sociais (em termos mais precisos, as estruturas do poder) e as estruturas mentais, correspondência que se estabelece por intermédio da estrutura dos sistemas simbólicos, língua, religião, arte etc" (BOURDIEU, 1992, p. 33).

Mas os mesmos sistemas simbólicos enquanto "instrumentos de conhecimento e comunicação" são estruturantes das estruturas mentais e estruturados por elas e, ainda, as estruturas mentais são estruturadas socialmente, justamente pelo caráter estruturante dos sistemas simbólicos... Vê-se, pois, que a gênese do campo - religioso e do campo social em geral - está nos sistemas simbólicos; princípio de constituição do socius, os sistemas simbólicos estão implicados desde já em qualquer análise que dos distintos campos que marcam a constituição do socius se possa realizar - por mais "primitivo" (histórica ou estruturalmente) que seja.

No entanto, a pergunta pela gênese dos sistemas simbólicos ou, mais precisamente, pela gênese do simbolismo em geral, como dissemos, está fora do escopo da pesquisa do socius. Fora num sentido radical que, segundo veremos, justamente uma certa linguística, que lida de uma certa forma, é capaz de sugerir: fora, porque para Bourdieu essa linguística deixa a desejar na medida em que não é uma "ciência adequada do discurso" (BOURDIEU, 1983, p. 161). Falta-lhe pesquisar a língua (e por isso a sua definição de língua é insuficiente) enquanto estrutura estruturante. Essa linguística, a de Saussure, só pesquisa a língua enquanto estrutura estruturada, colocando os falantes numa mesma posição perante ela, porquanto os torna meros atualizadores da sua estrutura, reduzindo, assim, a dimensão social da fala, ou seja, o discurso.

Enquanto para Saussure a língua (langue) é a estrutura abstrata da qual a fala (parole) é a atualização, para Bourdieu é o discurso enquanto emprego concreto da palavra que
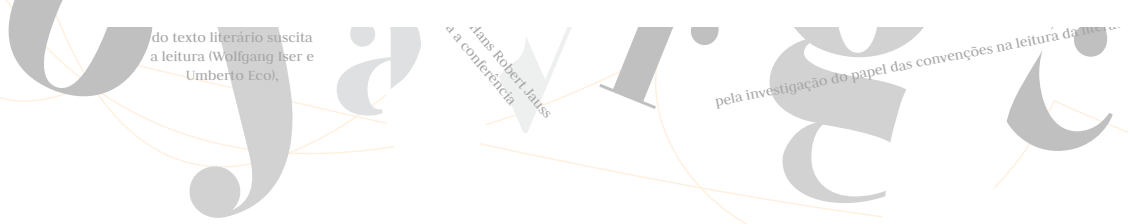
realmente estrutura língua. A língua de Saussure, cujas leis fonológicas encontram suas possibilidades de realização numa determinada fonética, é, se não uma abstração jamais encontrada no discurso, um construto ideológico: na medida em que Saussure esboça um esquema do aparelho fonador delimitando as zonas do mesmo com as quais se realizam os fonemas, não estaria mais que inscrevendo nesse modelo de aparelho fonador uma hexis (veja-se, no Curso de linguística geral, o "mapa" do aparelho fonador de Saussure).

Um exemplo imaginário: as pessoas que sofrem de "língua presa" não realizam os fonemas $/ \mathrm{s} / \mathrm{e} / \mathrm{z} /$, no seu lugar elas realizam os fones [f] e [v] (respectivamente), no entanto, em seus atos efetivos de proferir palavras, os dois segundos fones adquirem o valor dos dois primeiros fonemas: "[eu entendo muito bem o que vofê dif]"; "[a fofa entupiu, chamemov o deventupidor de fofa]". Este é apenas um exemplo baseado num distúrbio do aparelho fonador; de muito mais interesse são as expressões mencionadas por Bourdieu (1983, p. 179-80) referentes ao modo de pronunciar as palavras pelos falantes de diferentes posições sociais (da sociedade francesa), sendo a burguesia denotada pelos lábios enquanto que o "povo" é denotado pela "goela". o que esses exemplos nos mostram é que, mesmo na determinação da estrutura fonética da língua, há fatos de fala que devem ser considerados, questões de ordem social que teriam escapado a Saussure.

Porém, se Bourdieu encontra em Saussure um modelo de linguística que deve ser superado por uma mais adequada ciência do discurso, deixa ele, por sua vez, escapar tudo aquilo com que o problema do signo, como abordado por Saussure, poderia contribuir para a questão da gênese dos sistemas simbólicos, e não somente da língua, mas do simbolismo em geral e, a fortiori, do mesmo socius.

Embora reconheça o rigor das análises semiológicas desenvolvidas a partir do conceito saussuriano de signo, o veredito de Bourdieu em relação a esse conceito se estende a todos os seus usos: "O signo não tem existência (salvo abstrata, no dicionário) fora de um modo de produção lingüístico” (1983, p. 159). Quando se trata do signo no sentido mitológico de Lévi-Strauss, o problema se coloca da mesma forma: a estrutura do mito é uma abstração, pois enquanto é estudado como uma estrutura estruturada apresenta os mitos concretos como a sua atualização, sendo os signos míticos, por sua vez, abstrações, pois o seu emprego na construção dos mitos pela sociedade não é considerado pelo mitólogo de acordo com as questões sociológicas implicadas no poder de relatar concretamente os mitos, as condições sociológicas implicadas no poder de tomar a palavra e empregá-la no sentido mítico; assim, mutatis mutandis, o signo mítico também não tem existência (salvo abstrata, no repertório mitológico coligido pelo mitólogo) fora de um modo de produção mitológico.

O que essa linguística incompleta pode nos dizer acerca de um problema tão importante nas análises de Bourdieu, o simbolismo, do qual decorrem questões tão importantes como a dos sistemas simbólicos e a da violência simbólica? Enquanto tal linguística for lida naquilo que ela explicitamente coloca como contribuição positiva, nada além daquilo mesmo que Bourdieu pode nos apontar até agora: ela trata apenas de um dos sistemas simbólicos e, ainda, o apresenta somente enquanto estrutura estruturada, apontando ainda o lugar de uma semiologia decorrente das suas descobertas (mas sempre uma semiologia das estruturas estruturadas). Não se trata, pois, de impingir a Bourdieu uma leitura
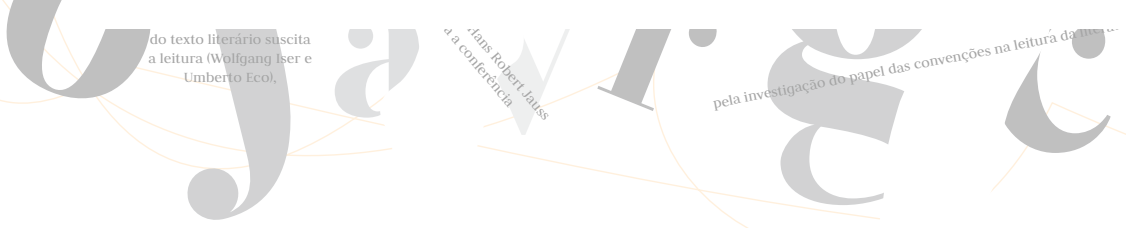
redutora dessa linguística, pois ele a compreendeu naquilo que ela quis dizer. Porém, se a lermos de outra forma - uma forma que nem mesmo a Bourdieu pareceria adequada, pois esta se liga a uma filosofia que, a seu ver, é paralisante - compreenderemos que o problema do signo coloca em pauta a própria abertura do anthropos para o simbolismo em geral, tanto em seu aspecto estruturado como em seu aspecto estruturante.

Ora, aceitando a crítica de Bourdieu a essa linguística, a saber, que ela, de partida, toma a comunicação "for granted", omitindo as condições de instauração da comunicação, podemos, por outro lado, dirigir a ele a mesma crítica quanto ao simbolismo: enquanto são os sistemas simbólicos que estruturam o mundo objetivo para os sujeitos e para o socius - jamais esquecendo-nos do circuito mencionado acima -, Bourdieu está tomando o simbolismo "for granted", deixando intocadas as condições de instauração do simbolismo. O mais próximo que ele chega de mencionar estas condições de instauração o encontramos na seguinte afirmação (que, ao que parece, não deixa de remeter-se à sua relação teórica com Durkheim):

Uma vez que os sistemas simbólicos derivam suas estruturas da aplicação sistemática de um simples principium divisionis e podem assim organizar a representação do mundo natural e social dividindo-o em termos de classes antagônicas; uma vez que fornecem tanto o significado quanto um consenso em relação ao significado através da lógica da inclusão/exclusão, encontram-se predispostos por sua própria estrutura a preencher funções simultâneas de inclusão e exclusão, associação e dissociação, integração e distinção. Somente na medida em que tem como sua função lógica e gnosiológica a ordenação do mundo e a fixação de um consenso a seu respeito, é que a cultura dominante preenche sua função ideológica - isto é, política -, de legitimar uma ordem arbitrária; em termos mais precisos, é porque enquanto uma estrutura estruturada ela reproduz sob forma transfigurada e, portanto, irreconhecível, a estrutura das relações sócio-econômicas prevalecentes que, enquanto uma estrutura estruturante (como uma problemática), a cultura produz uma representação do mundo social imediatamente ajustada à estrutura das relações sócio-econômicas que, doravante, passam a ser percebidas como naturais e, destarte, passam a contribuir para a conservação simbólica das relações de força vigentes. (apud. MICELI, 1992, p. XII)

O que seria esse "principium divisionis" de onde os sistemas simbólicos derivam a sua estrutura? Vemos que, em seguida da menção desse "princípio", a argumentação já entra no circuito estruturado-estruturante, mas fica claro que, aquém do circuito, está esse princípio que, ainda, diz Bourdieu, "é aplicado sistematicamente”. Ora, existe aplicação sistemática de um princípio fora de um sistema? É a sistematicidade de uma ação que funda um sistema, ou é do sistema que provém a sistematicidade de uma ação? Aporia que não nos levará muito longe. Deixando de lado a sua resolução, é o principium divisionis o que mais nos interessa.

A princípio porque é derivando a sua estrutura dele que os sistemas simbólicos "podem organizar a representação do mundo natural e social dividindo-o em classes antagônicas": antes de tudo, é a divisão, a diferença ou a inscrição da diferença entre natu-

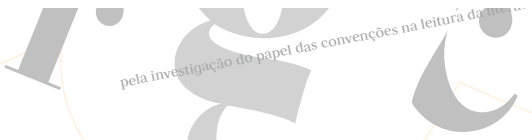


reza e sociedade (ou natureza e cultura) no mundo o que a aplicação sistemática deste princípio faz desde um princípio. E esta representação do mundo não pode mais que ser feita de si para si (seja por um indivíduo ou por uma coletividade), ou seja, incluindo-se aí o agente divisor na divisão; e a primeira divisão será, pois, a inclusão de si no socius, ou, ainda, a inscrição do socius sobre si. Que solidariedades para com um pensamento da natureza enquanto passividade afetada por um corte decisivo e irreversível, marcando o fim de uma instância primordial, onde o anthropos vivia sem a distinção, ou seja, sem a inscrição do socius sobre si e, portanto, sem essa violação da natureza do corpo chamada de habitus, haveria nessa ideia?

Que solidariedades, pois, com um pensamento e um discurso sobre a natureza do homem de viés rousseauista - que, conforme Derrida mostrou ${ }^{2}$, subjaz ainda ao discurso de Lévi-Strauss - haveria aí? São questões que, para serem respondidas, exigiriam um trabalho minucioso e, principalmente, conflituoso. Um trabalho que exigiria fazer exatamente aquilo que Bourdieu condena sob o termo filologismo: não se ater apenas ao sentido da palavra - neste caso, natureza - empregada aqui e agora, neste discurso, mas sim explorar os sentidos que sob a sua rubrica foram se sedimentando ao longo da história, apontando, então, aqui e ali, como essa natureza tem uma longa história no pensamento ocidental, rastreável pelo menos até a physis aristotélica.

Mas para o nosso problema, além do dito princípio e da sistematicidade da sua aplicação, interessa muito mais o fato de que as "classes antagônicas" em que a representação do mundo é organizada por essa aplicação "fornecem tanto o significado quanto um consenso em relação ao significado". Ora, enquanto os sistemas simbólicos derivam a sua estrutura dessa aplicação sistemática do principium divisionis, e enquanto a língua é somente um dos sistemas simbólicos, devemos deduzir que essa significação é anterior à significação em sentido linguístico e, a fortiori, que o signo linguístico deriva a sua estrutura dessa significação.

Por tanto, como apenas sugerimos anteriormente, seria abusivo impingir a Bourdieu o mote segundo o qual o meu mundo vai até onde vai a minha linguagem; mas seria justo entender que o mundo começa pelo signo e que, assim, a experiência do mundo e de si do anthropos - que deixou para trás a sua existência enquanto natureza no momento em que dividiu sistematicamente o mundo - começa pelo signo.

Convergências teóricas: a abertura para o não dito, a audição do inaudito

É a partir daqui, pois, que o recurso à linguística insuficiente de Saussure poderia dar subsídios a Bourdieu se lida, não de acordo com a sua tentativa de estabelecer os fatos positivos da língua e da fala - tentativa que demostra a sua insuficiência -, mas sim derivando-lhe a questão do signo por ela elaborada de forma negativa. Essa leitura, devemos assinalar, foi levada a cabo por Derrida (1973, p. 33-90), e isto nos coloca numa posição incômoda, pois, segundo Bourdieu, este filósofo não representa para ele um

“Já se desconfia - e todos os textos de Lévi-Strauss o confirmariam - que a crítica ao etnocentrismo, tema tão caro ao autor de Tristes Trópicos, na maior parte dos casos tem por única função constituir o outro como modelo da bondade original e natural, acusar-se e humilhar-se, exibir seu ser-inaceitável no espelho num espelho contra-etnocêntrico. Esta humildade de quem se sabe "inaceitável", este remorso que produz a etnografia, Rousseau os teria ensinado ao etnólogo moderno” (Derrida, 1973, p. 141-2).
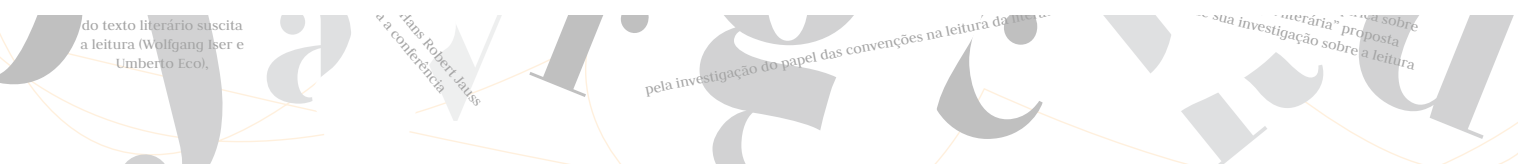
pensamento que tenha algo a contribuir com a sua problemática. De fato, a ele se refere como a uma espécie de "insurgente" desonesto para com as ciências sociais. Façamos, então, tal como o faz Bourdieu em relação a Marx, Weber e Durkheim quando se trata de pensar a gênese e a estrutura do campo religioso: "é preciso situar-se no lugar geométrico das diferentes perspectivas. Vale dizer, é preciso situar-se no ponto de onde se torna possível perceber, ao mesmo tempo, o que pode e o que não pode ser percebido a partir de cada um dos pontos de vista" (BOURDIEU, 1992, p. 28).

Saltando longos desenvolvimentos feitos por Saussure no Curso de linguística geral, situemo-nos na sua conclusão acerca da língua: a língua é uma forma, não uma substância. Extraindo as consequências dessa definição, Derrida desconstrói a noção contraditória de Saussure, segundo a qual a escrita seria uma representação da fala. Os passos dessa desconstrução nos levam diretamente ao problema do signo. Por economia, teremos de ser bastante sintéticos. Saussure, quando alcança a sua definição do signo linguístico, aponta dois aspectos: o signo é arbitrário e diferencial. Arbitrário: a relação entre significante e significado, quer dizer, a relação entre a ideia e a sequência de sons que conformam a palavra que se refere à ideia não é feita, por um lado, nem de acordo com uma escolha do indivíduo e, por outro lado, nem de acordo com qualquer necessidade imposta pela mesma ideia: a sequência de sons [cadeira] não guarda nenhuma semelhança para com o objeto ao qual se refere a ideia ou conceito de cadeira. Diferencial: os significantes extraem o seu poder de significar da diferença entre as suas formas: /pato/ /fato/ /gato/ só têm significados diferentes por virtude da diferença entre $/ \mathrm{p} /, \mathrm{f} / \mathrm{e} / \mathrm{t} /$. Por isso, ao fim e ao cabo, as diversas línguas extraem a sua diversidade justamente do fato de inscreverem de forma diversa as diferenças no fluxo sonoro. Assim, ao ouvido de um falante de língua espanhola, não há diferença entre [avó] e [avô] e, no entanto, ao ouvido do falante de português, essa diferença divide os conceitos de "pais do pai" e "pais da mãe" entre "mãe do pai" e "pai do pai", por um lado, e "mãe da mãe" e "pai da mãe" por outro. E esta diferença não se limita apenas às palavras: diz respeito também à tonalidade, por exemplo, que permite distinguir uma pergunta de uma afirmação, diz respeito também à posição das palavras numa frase, que permite entender qual é a função sintática que uma palavra desempenha de acordo com a posição que ocupa.

Comecemos por extrair as consequências deste segundo item definitório, a diferença. A significação provém, pois, da diferença, mas a diferença como tal jamais pode ser ouvida, apenas o seu efeito é que é dado à experiência: são os diferentes que são dados, mas não a sua diferença. Trate-se de explicar a diferença entre /fato/e /pato/: /pato/ começa com /p/e /fato/ começa com /f/... o que mais? O som de [p] se produz pela explosão entre os lábios superior e inferior, enquanto que o som de [f] se produz pelo encontro entre os dentes incisivos e o lábio inferior... faz-se uma descrição dos diferentes, mas não uma descrição da diferença. Pois a diferença é inaudível, mais ainda, ela é a condição de audibilidade dos diferentes. Exatamente o mesmo estado de coisas se dá quando se trata da língua escrita. E este é um dos fatos que permitirá a Derrida desconstruir a posição de Saussure, segundo a qual a escrita seria apenas um "acessório", um revestimento exterior da língua em seu funcionamento natural, que seria a fala. A fala é um tipo de escrita, de uma escrita geral que Derrida denominará a escritura (écriture):

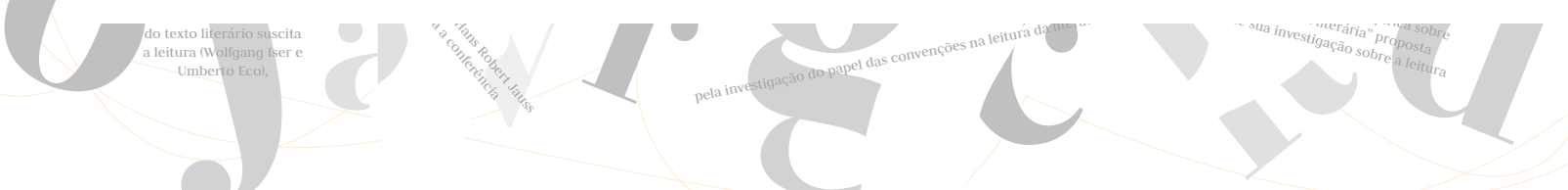


Não se trata pois de aqui reabilitar a escritura no sentido estrito, nem de inverter a ordem de dependência quando evidente [...]. Desejaríamos, antes, sugerir que a pretensa derivação da escritura, por mais real e sólida que seja, só fora possível sob uma condição: que a linguagem "original", "natural" etc., nunca tivesse existido, nunca tivesse sido intacta, intocada pela escritura, que sempre tivesse sido ela mesma uma escritura. Arquiescritura cuja necessidade aqui queremos indicar e cujo novo conceito queremos desenhar [...]. (DERRIDA, 1973, p. 68-69)

Vamos agora para o arbitrário, que deve ser examinado de perto com o caráter diferencial. Arbitrário não quer dizer, como apontamos, que seja de "livre escolha" de um indivíduo. Quer dizer simplesmente que a relação entre o significante e o significado é “imotivada". Ora, se as sequências de sons que se referem às ideias (ou seja, significam) o fazem em virtude - de acordo com o idioma - das articulações do som, articulações particulares para a ideia a ser referida, de onde provém a determinação de que seja esta articulação e não outra a requerida para referir-se a uma ideia, uma vez que não é uma escolha do indivíduo, nem da coletividade? De onde provêm essas e não aquelas diferenças significativas entre os fonemas? Para poder referir-se a uma situação como essa, em que a instituição de determinadas diferenciações não tem uma origem nem um sujeito determináveis é que Derrida acunhou a expressão rastro instituído.

Pode-se, em última instância, remeter à herança linguística a necessidade de que tais e tais diferenciações fônicas sejam aquelas a ter significatividade, mas isso só confirma que a diferença é a condição da hereditariedade e da significação. Há um rastro, pois, como dissemos: os elementos - o fone, o fonema, o grafema, as palavras, as frases - só significam enquanto diferendos dos demais elementos, ou seja, numa relação de remissão aos elementos ausentes, porém presentes. Um fonema, um grafema, uma palavra, uma frase, carregam o rastro dos elementos dos quais se diferenciam para significar. Mas um rastro invisível (ou inaudível). O raciocínio se estende a ambas as partes do signo. Que o significante seja significativo e que essa significatividade seja produto da diferença e do rastro quer dizer que o significado - o pensamento, a ideia, o conceito - também o é, pois o significado de uma palavra é sempre outra(s) palavra(s), cujo(s) significado(s) provém de outra(s) palavra(s), e assim, ad infinitum. É, pois, o próprio signo que é uma escrita, pois a significação, a remissão do significante para o significado, se opera por virtude da diferença e do rastro; dizer que se passa do significante para o significado, é dizer que se passa de rastro para rastro, de diferença para diferença:

Estas cadeias e estes sistemas podem-se desenhar somente no tecido deste rastro ou imprensão. A diferença inaudita entre o aparecendo e o aparecer (entre o "mundo" e o "vivido") é a condição de todas as outras diferenças, de todos os outros rastros, e ela já é um rastro [...]. O rastro é verdadeiramente a origem absoluta do sentido em geral. $O$ que vem a afirmar mais uma vez que não há origem absoluta do sentido em geral. $O$ rastro é a diferência [diférrance] que abre o aparecer e a significação. (DERRIDA, 1973, p. 79-80) 
Qual é o sentido dessa leitura que faz Derrida de Saussure para o nosso problema? É que dessa leitura Derrida extrai conclusões que nos levam para muito além da fala, da língua e da mesma linguística. Diz respeito à mesma possibilidade de dar um sentido ao mundo e dar um sentido à experiência do mundo. Veremos que dirá respeito àquela aplicação sistemática do principium divisionis colocada por Bourdieu.

Do rastro e da diferença como fontes invisíveis e inaudíveis da própria significação, resulta que as oposições ou antagonismos conceituais que uma determinada forma de pensar o mundo possa fazer já são derivadas, na medida em que a diferença e o rastro remetem todos os conceitos entre si, sem impor a priori a formação de pares. Daí se pode notar que o próprio recorte linguístico do mundo não passa também de uma derivação da constituição do mundo operada pela diferença e pelo rastro.

É onde se dá o improvável encontro entre Derrida e Bourdieu, e onde nos situamos naquele "ponto geométrico". Um passo adentro a mais que Bourdieu houvesse ousado a dar no texto de Saussure (e um pouco a mais de tolerância para com Derrida e o seu estilo de filosofar), e poderia ter-se colocado no ponto geométrico que lhe permitiria notar que a mesma "aplicação sistemática de um principum divisionis", dos quais os sistemas simbólicos "derivam a sua estrutura”, já é uma derivação desse trabalho da diferença e do rastro que é a mesma fonte de todo e qualquer princípio de organização (seja esta a divisão, a oposição, a tripartição ou qualquer classificação em geral). Uma derivação e, acima de tudo, uma repressão da diferença, que na história da estruturação dos sistemas simbólicos permitiu que se instaurassem sistemas conceituais que impuseram, com consequências para as próprias ciências sociais, denominações, distinções e oposições acríticas e não científicas como, por exemplo, a noção de "povo sem escrita”.

Quando Derrida ${ }^{3}$ aponta a subjacência de um preconceito como esse nos textos de Lévi-Strauss, Bourdieu aponta esse gesto como uma "insurgência" contra as ciências sociais. E, no entanto, para além desse antagonismo aparente, Bourdieu, pensamos, está trabalhando, justamente, por uma, digamos, liberação da diferença.

\section{A fenda aberta: considerações finais}

Retornemos para a cena da entrevista. Aonde há de ser conduzido o pesquisador por meio da "escuta metódica"? Aonde conduz, pois, esse "reduzir ao máximo a violência simbólica"? Ora, se bem compreendemos, a sua ciência social, que denuncia as arbitrariedades das instituições que querem fazer passar por naturais as relações de poder e de exclusão que mantêm oprimidas as classes dominadas, tem como um de seus objetivos desmascarar constantemente essa falsa natureza. O que ela pretende mostrar ou demonstrar por entre a fenda que o seu estilo rasga no véu das relações de poder

"À expressão "sociedade sem escritura” não corresponderia, pois, nenhuma realidade nem nenhum conceito. Esta expressão provém do onirismo etnocêntrico, abusando do conceito vulgar, isto é, etnocêntrico, da escritura [...]. Os Nhambiquar - o sujeito da "Lição de escritura" - seriam, portanto, um destes povos sem escritura. Não dispõem daquilo que nós denominamos escritura no sentido corrente. Isto é, em todo caso, o que nos diz Lévi-Strauss: “Supõe-se que os Nhambiquara não sabem escrever". Logo adiante esta incapacidade será pensada, na ordem ético-política, como uma inocência e uma não-violência interrompidas pela efratura ocidental e pela “Lição de escritura”. Assistiremos a esta cena” (DERRIDA, 1973, p. 72).
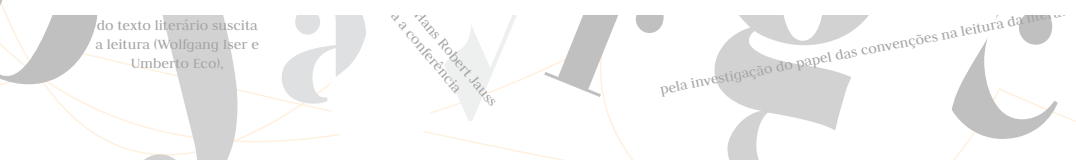
instauradas pelas instituições é algo que nos parece incerto, mas que podemos sugerir uma vez que tratamos de situar Bourdieu num pensamento da diferença.

Talvez, o que aparece nessa fenda aberta - cuja abertura deve ter a duração de um piscar de olhos, pois o poder é autorregenerativo: a sempre anunciada e nunca cumprida destruição do capital é uma amostra disso - seja, não uma humanidade perdida, um anthropos num estado idílico, rousseauista, mas sim um anthropos que antes de organizar-se em estruturas opositivas, antagônicas e excludentes, estabelece a sua relação com o outro pela diferença. Pela diferença, repetimos, e não apenas por algumas das possíveis estruturas que dela se derivam, a oposição, o antagonismo e a exclusão. E repetimos também as perguntas acerca do que trata de ouvir a “escuta metódica”. Já vimos o que é ouvido:

em mais de um caso nós sentimos que a pessoa interrogada aproveitava a ocasião que lhe tinha sido dada de ser interrogada [...] para realizar um trabalho de explicitação, gratificante e doloroso ao mesmo tempo, e para enunciar, às vezes com uma extraordinária intensidade expressiva, experiências e reflexões há muito reservadas ou reprimidas. (BOURDIEU, 1997, p. 704-5)

A redução da violência simbólica opera uma libertação da experiência. Essa redução deve ser capaz, caso se trate de compreender o entrevistado, de ir buscar o seu ponto de vista: "tomar assim o seu ponto de vista, isto é, compreender que se estivesse, como se diz, no seu lugar, ele seria e pensaria, sem dúvida, como ele" (BOURDIEU, 1997, p. 713). Ser como, pensar como... como quem? Como o outro. Como o outro, porém não mais como o outro no sentido opositivo, distintivo, excludente dessa estruturação arbitrária da relação eu-tu que se trata de reduzir. o outro: o diferente.

Que o registro dessa escuta representa um risco, o risco de se perder a singularidade dessa expressão da diferença que foi liberada, Bourdieu o indica intitulando "os riscos da escrita" a seção de seu texto que trata do registro da entrevista. São diversas as perdas de gestos, olhares, tons de voz, repetições decorrentes da transcrição da edição textual das gravações. Diversas são também as que decorrem da exclusão de frases que dão informações acerca do entrevistado e de terceiros cuja exclusão é prescrita pela ética da pesquisa. Mas, afora essas "perdas", todo o cuidado da escuta metódica parece dar-se em torno de não perder a diferença que se inscreve na expressão dessa pessoa singular, cujo discurso está se tratando de arrancar das determinações impostas pelos sistemas simbólicos.

Não apenas compreender, sendo-como e pensando-como o entrevistado enquanto um sujeito que ocupa uma determinada posição na sociedade, mas também compreender o entrevistado enquanto uma singularidade cuja diferença foi reprimida pelo seu posicionamento na sociedade. Ouvir, escutar, compreender o rastro e a diferença que o sujeito inscrito no socius carrega consigo enquanto a marca da sua singularidade antes de ser mais um - número, nome, endereço, profissão, homem, mulher, homossexual, heterossexual, negro, branco, rico, pobre, pai, mãe... - no socius, na cultura. o ponto onde o pesquisador se posiciona para realizar a sua escuta metódica é, pois, no limite, na tênue fronteira - e aqui finalmente podemos usar esse termo no sentido que cremos adequado para a nossa reflexão - onde termina a singularidade do indivíduo e começa

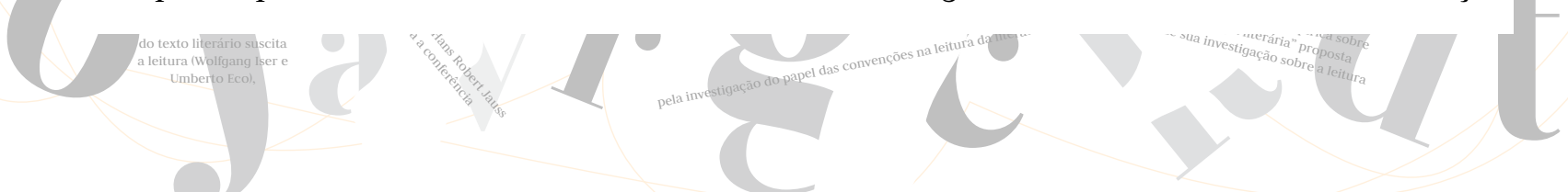


a sociedade, na qual o anthropos se torna anthropo-logico. Tênue, pois em ciências sociais dificilmente se concede ao indivíduo qualquer autonomia para com as relações materiais de existência: as relações socioeconômicas. Talvez o mesmo Bourdieu não nos concedesse a demarcação dessa fronteira em seus textos.

A Biagraphía, dizíamos, terá que ir muito além nas reflexões que fizemos aqui antes mesmo de construir e prescrever qualquer código para o registro da violência. Perguntar-se se, de direito, a experiência da violência é registrável: pode-se registrar, ou seja, tornar pública e legível, uma experiência cujo registro mnésico e corporal é da ordem da singularidade do indivíduo?

Antes de lançar-se aos códigos e métodos de registro, o biágrafo (aquele que registra a Biagraphía) terá que se instalar plenamente nessa fenda aberta pelo estilo de Bourdieu, e praticar a escuta atenta e metódica da expressão inaudível da diferença, que lhe chega aos ouvidos do mais além da fronteira do socius. Ou ainda, do mais além da fronteira de uma anthropo-logia.

\section{Referências Bibliográficas}

BOURDIEU, P. “Compreender”. In: A miséria do mundo. Trad. Mateus S. Soares Azevedo et al. Petrópolis: Vozes, 1997.

“ “Sobre o poder simbólico". In: o poder simbólico. Trad. Fernando Tomaz. Rio de Janeiro: Bertrand do Brasil, 2003.

. "Gênese e estrutura do campo religioso". In: MICELI, S. (org.). A economia das trocas simbólicas. São Paulo: Perspectiva, 1992.

"A economia das trocas linguísticas". In: ORTIZ, R. (Org.). Pierre Bourdieu: Sociologia. São Paulo: Ática, 1983.

DERRIDA, J. Gramatologia. Trad. Miriam Chnaiderman; Renato Janine Ribeiro. São Paulo: Perspectiva, 1973.

MICELI, S. "A força do sentido". In: (Org.). A economia das trocas simbólicas. São Paulo: Editora Perspectiva, 1992.

SAUSSURE, F. Curso de Linguística Geral. Trad. Antônio Chelini. São Paulo: Cultrix, 1983.

ARTIGO RECEBIDO EN: 18 ago. 2012

ArTigo ACEITO Ev: 12 set. 2012

REFERÊNCIA ELETRÔNICA: NUESCH, Enrique V. Por uma biagraphia: notas sobre o registro da violência. Revista Criação \& Crítica, n. 9, p. 174-186, nov. 2012. Disponível em: <http://www.revistas.usp.br/criacaoecritica>. Acesso em dd mmm aaaa.
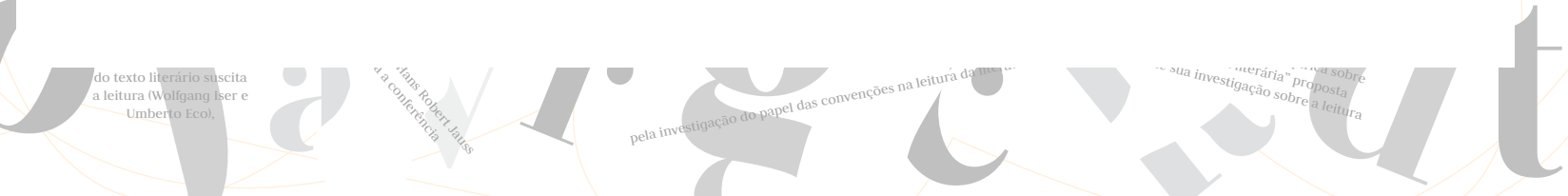